Juwon Lee - Svetlana E. Kotliarova - Ashraf A. Ewis

Akiko Hida • Toshikatsu Shinka • Yoko Kuroki

Katsushi Tokunaga • Yutaka Nakahori

\title{
Y chromosome compound haplotypes with the microsatellite markers DXYS265, DXYS266, and DXYS241
}

Received: September 4, 2000 / Accepted: November 16, 2000

\begin{abstract}
Two newly developed microsatellite markers on Yp11 (DXYS265) and Yq11.21 (DXYS266) and our previously reported marker, on Yp11 (DXYS241), were typed by triplex polymerase chain reaction (PCR) in 102 Japanese, 18 white American, and 17 black American males. The DXYS265 locus revealed three alleles, the DXYS266 locus showed two alleles, while the DXYS241 locus showed five alleles. Nine different compound haplotypes were observed among the males. Of these, two haplotypes were common to all groups, while four were limited to Japanese. Pedigree analysis of 61 Japanese families revealed no mutations of these loci. The triplex PCR developed in this study, as well as the new loci, are useful for tracing paternal lineages in human migration studies and population analysis, in addition to Y chromosome evolutionary studies.
\end{abstract}

Key words $\mathrm{Y}$ chromosome $\cdot$ Microsatellite $\cdot$ Polymorphism · Haplotypes · DXYS241 · DXYS265 · DXYS266 · Japanese

\section{Introduction}

Since the first discovery of Y chromosome DNA polymorphisms (Casanova et al. 1985), it has been suggested that the non-recombining portion of the $\mathrm{Y}$ chromosome provides a system to trace paternal lineages for evolutionary and other studies (Ngo et al. 1986; Nakagome et al. 1992; Karafet et al. 1999). However, progress in these areas has been slow, because it has been difficult to find suitable markers

J. Lee · A.A. Ewis · T. Shinka · Y. Kuroki · Y. Nakahori $(\triangle)$

Department of Public Health, School of Medicine, University of

Tokushima, 3-18-15 Kuramoto-cho, Tokushima 770-8503, Japan

Tel. +81-88-633-7075; Fax +81-88-633-7453

e-mail: nakahori@basic.med.tokushima-u.ac.jp

S.E. Kotliarova

Laboratory for CAG Repeat Diseases, Brain Science Institute,

RIKEN, Saitama, Japan

A. Hida $\cdot$ K. Tokunaga

Department of Human Genetics, Graduate School of Medicine,

University of Tokyo, Tokyo, Japan
(Jobling and Tyler-Smith, 1995). Recently, a series of markers became available, and the pedigree of males has been well summarized (Jobling and Tyler-Smith, 2000).

The DNA polymorphisms used for such studies are classified into two groups. The first group consists of biallelic markers with a low mutation rate, which may represent rare events occurring only once during the long history of human evolution (i.e., many single nucleotide polymorphisms and insertions of Alu repeat elements in particular sites). The second group consists of multiallelic markers with a relatively high mutation rate in human evolution, possibly representing independent mutational events in respective male lineages. The former seems useful to study the deep roots of the human genetic evolution tree, while the latter is useful to study more recent evolution within limited ethnic groups. In other words, studying microsatellite markers can reveal the relationship between haplotypes constructed with biallelic markers, and is, thus, potentially useful for microevolution studies of the Y chromosome (Jobling and TylerSmith 1995; Hammer 1995).

The first microsatellite marker on the X-Y homologous nonrecombining region of the $\mathrm{Y}$ chromosome (pentanucleotide) was described in 1994 (Chen et al. 1994). Several Y chromosome-specific microsatellite markers have become available for forensic, population genetics, and evolutionary studies. Most of these markers showed genetic diversity among individuals in a single population rather than between populations (Hammer et al. 1997). Recently, efforts to obtain a series of Y-specific microsatellite markers have been made (Mathias et al. 1994 and Cooper et al. 1996). These microsatellite markers show genetic Y chromosomal heterogeneity within and between populations and are used to trace the human evolutionary process on a historical time scale (Underhill et al. 1996). Although these studies are done on a worldwide scale and the origin of Japanese males is roughly mapped on the pedigree, these origins are vague, in contrast with the detailed map of European male groups. Therefore, further markers to divide Japanese males are required.

In an attempt to obtain markers useful for the study of recent male evolution, we are trying to establish more poly- 
morphic microsatellite markers in Japanese males. In this study, two newly developed CA markers, on Yp11 (DXYS265) and Yq11.21 (DXYS266) and our previously reported marker on Yp11 (DXYS241) (Kotliarova et al. 1999) were typed by triplex polymerase chain reaction (PCR). Allele frequencies on the Y chromosome, as well as mutation rates and compound haplotypes, were studied. The triplex PCR is potentially useful for studying human migrations, and is complementary to other polymorphism analysis.

\section{Materials and methods}

Isolation of DXYS265 and DXYS266 from a cosmid library

A cosmid library was constructed from yOX38 YAC and yOX219 YAC, using the Stratagene SperCosI protocol (Stratagene, La Jolla, CA, USA). The YAC was isolated from the YAC library, described by Foote et al. (1992), and derived from the distal part of the short arm of the $\mathrm{Y}$ chromosome. The colonies were blotted to Hybond-N nylon membranes (Amersham, Arlington, Heights, IL, USA) according to the manufacturer's protocol. Colonies with $(\mathrm{CA})_{\mathrm{n}}$ repeats were selected by hybridization with a $(\mathrm{CA})_{20}$ oligonucleotide probe labeled with $\left(\alpha-{ }^{32} \mathrm{P}\right)$ deoxyadenosine triphosphate (dATP; Amersham), using a T4 polynucleotide-kinase labeling kit (Takara, Tokyo, Japan). Prehybridization and hybridization were performed in a mixture of $6 \times$ standard saline citrate (SSC), $1 \times$ Denhardt's solution, $0.1 \%$ sodium dodecylsulfate (SDS), and $0.1 \mathrm{mg} / \mathrm{ml}$ salmon sperm DNA at $42^{\circ} \mathrm{C}$ overnight. The concentration of the probe was $0.5 \times 10^{6}$ to $1 \times 10^{6}$ counts per $\min (\mathrm{cpm}) / \mathrm{ml}$. Washes were performed in $6 \times \mathrm{SSC}$ and $0.1 \%$ SDS at $42^{\circ} \mathrm{C}, 40^{\circ} \mathrm{C}$, and $55^{\circ} \mathrm{C}$ for $10 \mathrm{~min}$ consecutively. Each filter was exposed to a Kodak X-ray film overnight at $-70^{\circ} \mathrm{C}$.

\section{Sequencing of cosmid DNA}

Cosmid DNA was isolated using a Quiagen Plasmid Kit (Quiagen, Hilden, Germany). The sequencing primers were $5^{\prime}-(\mathrm{CA})_{10} \mathrm{G}-3^{\prime}, 5^{\prime}-(\mathrm{CA})_{10} \mathrm{~A}-3^{\prime}, 5^{\prime}-(\mathrm{CA})_{10} \mathrm{~T}^{\prime}-3^{\prime}, 5^{\prime}-(\mathrm{CA})_{10} \mathrm{CG}-$ $3^{\prime}, 5^{\prime}-(\mathrm{CA})_{10} \mathrm{CC}-3^{\prime}$, and $5^{\prime}-(\mathrm{CA})_{10} \mathrm{CT}-3^{\prime}$. Sequencing was performed on an Applied Biosystems DNA sequencer (ABI 377; PE Biosystems, Norwalk, CT, USA), using an ABI Prism dye terminator cycle sequencing reaction kit. As a result, a CA-strand or reverse primer was developed, and this was used as the sequencing primer for the same cosmid template to develop a forward or GT-strand primer.

\section{DNA samples}

Genomic DNAs were prepared from peripheral leukocytes according to the standard method (Sambrook et al. 1989). Blood samples from Japanese males were collected from healthy blood donors. These samples were derived from families, and we selected only fathers to estimate allele frequencies at three loci (DXYS241, DXYS265, and DXYS266). For the other two ethnic groups, we used DNA from white and black males from the United States.

\section{Microsatellite genotyping}

Triplex genotyping of the three $\mathrm{Y}$ chromosome microsatellites - DXYS241, DXYS265, and DXYS266 was done using the ABI 377 sequencer. The PCR reaction contained three sets of primer pairs, one of which was endlabeled with fluorescent dyes, as described below. DNA samples were amplified by PCR in a volume of $10 \mu \mathrm{l}$ containing 66ng genomic DNA, $67 \mathrm{mM}$ Tris- $\mathrm{HCl}(\mathrm{pH} 8.3)$, $3 \mathrm{mM} \mathrm{MgCl}_{2}, 16.6 \mathrm{mM}\left(\mathrm{NH}_{4}\right) \mathrm{SO}_{4}, 0.1 \mathrm{mM}$ dNTPs, $0.5 \mu \mathrm{M}$ of each primer, and $1 \mathrm{U}$ Taq Gold DNA polymerase. Primer concentrations were optimized for each triplex PCR panel. Thermocycling was performed using a PE9600 thermocycler (PE Biosystems) under the following conditions: initial denaturation at $95^{\circ} \mathrm{C}$ for $12 \mathrm{~min}$, followed by 30 cycles of denaturation at $95^{\circ} \mathrm{C}$ for $30 \mathrm{~s}$, ramping slowly to $60^{\circ} \mathrm{C}$ within $2 \mathrm{~min}$, annealing at $60^{\circ} \mathrm{C}$ for $30 \mathrm{~s}$, and extension at $72^{\circ} \mathrm{C}$ for $1 \mathrm{~min}$. The final extension step was at $72^{\circ} \mathrm{C}$ for $30 \mathrm{~min}$. PCR products were resolved with urea denaturing polyacrylamide gels on the ABI sequencer, using an internal size standard in each lane. Raw genotype data were collected using Genescan software (ABI), and gel files were analyzed with the Genotyper software package (ABI).

The primers used for PCR were labeled as follows: the DXYS265 F primer was labeled with FAM; the DXYS266 F primer was labeled with HEX; the DXYS241 F primer was labeled with TET.

\section{Fluorescence in situ hybridization}

DXYS265 and DXYS266 were found to localize on human Y chromosomes, using fluorescence in situ hybridization (FISH), according to the protocols outlined by Takahashi et al. (1992) and Hirai et al. (1994). In brief, the probe was labeled with biotin, using a nick translation kit (GIBCOBRL, Grand Island, NY, USA). The quantity of probe DNA per slide was either 20-300ng of cosmid or 4$5 \mu \mathrm{g}$ of YAC. A mixture of a denatured biotinylated probe and cot-1 DNA was added to an equal volume of the hybridization solution. The chromosomes were denatured with $70 \%$ formamide in $2 \times \mathrm{SSC}$ at $70^{\circ} \mathrm{C}$ for $2 \mathrm{~min}$, and then the slides were dehydrated in an ethanol series: $70 \%, 90 \%$, and $100 \%$ for 5,4 , and $3 \mathrm{~min}$, respectively, followed by drying. The probe mixture was placed on a slide, covered with parafilm, and kept overnight in a humid chamber. The first signal amplification was carried out with antibiotin antibodies (Enzo Biochem, New York, NY, USA). The second signal amplification was performed with fluoresceinisothiocyanate (FITC)-labeled goat anti-rabbit IgG. Goat anti-rabbit IgG (Enzo Biochem) was diluted 1:100 in $4 \times$ SSC containing bovine serum albumin (BSA) (Boehringer, $\mathrm{GmbH}$, Germany). Chromosomes were counterstained with propidium iodide (Sigma, St. Louis, MO, USA). 


\section{Results}

\section{Development of DXYS265 and DXYS266}

The cosmids $21 \mathrm{H}-38 \mathrm{H}$ and A2-1-219 containing CA repeats were isolated from the cosmid library constructed from the yOX38 YAC and yOX219 when oligonucleotide (CA $)_{20}$ was used as a probe. The flanking sequence of the repeat was determined by sequencing cosmid DNA, using one of the six primers $5^{\prime}-(\mathrm{CA})_{10} \mathrm{~N}-3^{\prime}$. The reverse sequencing primer was developed using these sequence data. Subsequently, second forward PCR primers were selected. The primer sequences were:

DXYS241: $38 \mathrm{Y}-38 \mathrm{ZR}$

5'-ATAAATGCCTATGGGGCACG-3'

$38 \mathrm{Y}-38 \mathrm{ZF}$ :

5'-GGGTTTTAGCCACATAATCAGC-3'

DXYS265: $21 \mathrm{H}-38 \mathrm{CA}$ :

5'-CAACTTTCCTTTCATTTTCCAG-3'

$21 \mathrm{H}-38 \mathrm{HR}$ :

5'-GCTAACCTAGTTTTCCCAGACA-3'

DXYS266: A2-1-219F:

5'-CTGTCATCACTGAGTCTCAC-3'

A2-1-219R:

5'ATAAATCTCTCCAAATATTTTAC-3'

\section{Chromosomal localization of DXYS265 and DXYS266}

To verify the chromosome origin of the newly developed (CA $)_{n}$ markers, we carried out a PCR check on a panel of rodent-human somatic cell hybrids, each carrying one human chromosome and together representing the full human chromosome complement. Amplification was observed exclusively in hybrids that carried the $\mathrm{Y}$ chromosome or $\mathrm{X}$ chromosome.

The results of FISH demonstrated localization of DXYS265 on Yp11, while DXYS266 was localized on Yq11.21 in the X-Y homologous region of the human $Y$ chromosome. On the X chromosome, DXYS265 was localized on Xq21.2, while DXYS266 was localized on Xq21.3 (data not shown). The alleles on the $\mathrm{X}$ and $\mathrm{Y}$ chromosomes at these three loci were found to be of different, nonoverlapping sizes.

Allele frequencies

Allele frequencies were estimated from the analysis of 102 unrelated males of Japanese origin, 18 United States white males, and 17 United States black males.

On the Y chromosome, the microsatellite locus DXYS241 had three alleles in Japanese males, 225, 227, and 229 , which carried the $(\mathrm{CA})_{13},(\mathrm{CA})_{14}$, and $(\mathrm{CA})_{15}$ repeats, respectively. The United States white males had alleles 227 , 229, and 231, while in the United States black males, the alleles 223, 227, 229, and 231 were detected at the same locus. The DXYS265 locus showed three alleles on the Y chromosomes of Japanese males, 162, 164, and 166, which
Table 1. Sizes and frequencies of the alleles of the CA repeat polymorphism in loci DXYS241, DXYS265, and DXYS266 in three different ethnic groups

\begin{tabular}{llll}
\hline Size & Japanese & US Whites & US Blacks \\
\hline DXYS241 & & 0 & \\
$223\left(\mathrm{CA}_{12}\right)$ & 0 & 0 & 0.06 \\
$225\left(\mathrm{CA}_{13}\right)$ & 0.38 & 0.69 & 0.82 \\
$227\left(\mathrm{CA}_{14}\right)$ & 0.59 & 0.12 & 0.06 \\
$229\left(\mathrm{CA}_{15}\right)$ & 0.03 & 0.19 & 0.06 \\
$231\left(\mathrm{CA}_{16}\right)$ & 0 & & \\
DXYS265 $_{162\left(\mathrm{CA}_{12}\right)}$ & 0.62 & 1.00 & 0 \\
$164\left(\mathrm{CA}_{13}\right)$ & 0.36 & 0 & 0 \\
$166\left(\mathrm{CA}_{14}\right)$ & 0.02 & 0 & 0.94 \\
DXYS266 $_{212\left(\mathrm{CA}_{16}\right)}$ & 0.85 & & 0.06 \\
$214\left(\mathrm{CA}_{17}\right)$ & 0.15 & 0.75 & \\
\hline
\end{tabular}

had $(\mathrm{CA})_{12},(\mathrm{CA})_{13}$, and $(\mathrm{CA})_{14}$ repeats, respectively. The United States white and United States black males showed only allele 162 at the same locus. The DXYS266 locus also showed two alleles on all the Y chromosomes, of the Japanese, United States white, and United States black males, 212 and 214, which carried the $(\mathrm{CA})_{16}$ and $(\mathrm{CA})_{17}$ repeats, respectively (Table 1 ).

\section{Compound haplotypes}

Using combinations of $\mathrm{Y}$ chromosome alleles of the three microsatellite loci to construct haplotypes, we found that there were nine different haplotypes in total. Of the nine, seven were observed among Japanese males, four among United States white, and four among United States black males.

For the Y chromosome, the haplotype (162/212/227) showed the highest prevalence rates, of $44 \%, 62.5 \%$, and $81.1 \%$, among Japanese, United States white, and United States black males, respectively (Table 2). The next most frequent haplotype (164/212/225), found in $34 \%$ of Japanese males, was not observed in the other populations. Four haplotypes were observed only in Japanese, while two were not observed in Japanese.

\section{Discussion}

In this study, we reported two new microsatellite markers (DXYS265 and DXYS266) that were developed in the $\mathrm{X}-\mathrm{Y}$ homologous nonrecombining portion of the $\mathrm{Y}$ chromosome. The triplex PCR system and these markers, together with a previously described marker (DXYS241), were developed and used to study the allele frequencies on the $\mathrm{Y}$ chromosomes, as well as the mutation rate at these loci and haplotype analysis of a Japanese population and two other populations, of United States whites and United States blacks. In all the studied populations, the most frequent Y chromosome alleles were 162, 212, and 227 at DXYS265, DXYS266, and DXYS241, respectively. These 
Table 2. Nine haplotypes on Y chromosomes constructed from the alleles of the three microsatellite markers

\begin{tabular}{|c|c|c|c|c|c|}
\hline \multicolumn{3}{|c|}{ Compound haplotypes } & \multicolumn{3}{|c|}{ Percentage of haplotypes in } \\
\hline DXYS265 & DXYS266 & DXYS241 & Japanese & US Whites & US Blacks \\
\hline 162 & 212 & 223 & 0 & 0 & 6.3 \\
\hline 162 & 212 & 225 & 2.0 & 0 & 0 \\
\hline 162 & 212 & 227 & 44.0 & 62.5 & 81.1 \\
\hline 162 & 212 & 229 & 3.0 & 12.5 & 6.3 \\
\hline 162 & 214 & 227 & 13.0 & 6.2 & 0 \\
\hline 162 & 214 & 231 & 0 & 18.8 & 6.3 \\
\hline 164 & 212 & 225 & 34.0 & 0 & 0 \\
\hline 164 & 214 & 227 & 2.0 & 0 & 0 \\
\hline 166 & 212 & 225 & 2.0 & 0 & 0 \\
\hline
\end{tabular}

results are consistent with our previous report indicating that the 227 allele is the major allele at the DXYS241 marker in the Japanese population (Kotliarova et al. 1999).

Compound haplotyping, using the three loci, resulted in the detection of nine haplotypes. Of these, seven were observed in the Y chromosomes of Japanese males and four different haplotypes were seen among the United States white and United States black males. Some haplotypes were common to each population and others were unique. Because the number of samples from the United States was limited, we cannot conclude that the lack of cases represents lack of the haplotypes in the United States population. Still, these haplotypes seem to be Japanese-specific haplotypes that were not shared by the other two populations. These Japanese-specific Y haplotypes were (DXYS265/ DXYS266/DXYS241), (164/212/225), (162/212/225), (164/ 214/227), and (166/212/225), which showed prevalence rates of $34 \%, 2 \%, 2 \%$, and $2 \%$, respectively.

There is controversy about using $\mathrm{Y}$ chromosome microsatellite markers. Some surveys have assumed that $\mathrm{Y}$ chromosome microsatellites have a mutation rate comparable to, if not higher than, autosomes, which indicates that $\mathrm{Y}$ chromosome microsatellites would be of little use for creating a human genetic evolutionary tree (Heyer et al. 1997; Kayser et al. 2000). Other researchers have found evidence from Y-specific microsatellite data about trends of genetic affinities among ethnically and geographically related populations (Parra et al. 1999).

To address this issue, we also investigated the pattern of inheritance of these repeats by carrying out pedigree analysis of 61 Japanese families; a total of 293 individuals. No mutation events that could lead to a change in the CA repeat number on $\mathrm{X}$ and $\mathrm{Y}$, or recombination events on the $\mathrm{X}$ chromosome, were detected. This indicates that these repeats have passed through generations without mutations.

These three Y chromosome microsatellite loci, with their ability to pass unchanged through generations, can be considered useful tools for tracing population roots, together with other polymorphisms. Because it has been indicated that the study of microsatellite markers potentially reveals the relationship between haplotypes constructed with biallelic markers (Jobling and Tyler-Smith 1995), we correlated our results for the microsatellite haplotypes con- structed here and our previously reported haplotypes using biallelic loci (47Z, YAP, and SRY) (Shinka et al. 1999) in some of the samples. The results showed that the haplotype (162/212/227) was usually linked with haplotype I (Y1, YAP-, and C) or haplotype II (Y1, YAP+, and C), while haplotype (164/212/225) was usually linked with haplotype III (Y1, YAP-, and S) or haplotype IV (Y2, YAP-, and S).

In conclusion, these new markers will be valuable for studies in which nonrecombining, gender-specific DNA markers are required. They can help in forensic investigations, as well as in studies of populations and their evolutionary histories, especially in terms of microevolutionary events.

Acknowledgments This work was supported by grants from the Ministry of Health and Welfare of Japan and from the Ministry of Education, Science, and Culture of Japan. S.E. Kotliarova was supported by a JSPS Postdoctoral Fellowship, P-9511.

\section{References}

Casanova M, Leroy P, Boucekkine C, Weissenbach J, Bishop C, Fellous M, Purrelo M, Fiori G, Siniscalco M (1985) A human Ylinked DNA polymorphism and its potential for estimating genetic and evolutionary distance. Science 230:1403-1406

Chen H, Lowther W, Avramopoulos D, Antonarakis SE (1994) Homologous loci DXYS156X and DXYS156Y contain a polymorphic pentanucleotide repeat (TAAAA) ${ }_{n}$ and map to human $\mathrm{X}$ and $\mathrm{Y}$ chromosomes. Hum Mut 4:208-211

Cooper G, Amos W, Hofman D, Rubinsztein DC (1996) Network analysis of human Y microsatellite haplotypes. Hum Mol Genet 5:1759-1766

Foote S, Vollrath D, Hilton A, Page DC (1992) The human Y chromosome: overlapping DNA clones spanning the euchromatic region. Science 158:60-66

Hammer MF (1995) A recent common ancestry for human Y chromosomes. Nature 378:376-378

Hammer MF, Spurdle AB, Karafet T, Bonner MR, Wood ET, Novelletto A, Malaspina P, Mitchell RJ, Horai S, Jenkins T, Zegura SL (1997) The geographic distribution of Y chromosome variation. Genetics 145:787-805

Heyer E, Puymirat J, Dieltjes P, Bakker E, de Knijff P (1997) Estimation of $\mathrm{Y}$ chromosome specific microsatellite mutation frequencies using deep rooting pedigrees. Hum Mol Genet 6:799-803

Hirai M, Suto Y, Kanoh M (1994) A method for simultaneous detection of fluorescent G-band in situ hybridization signals. Cytogenet Cell Genet 66:149-151

Jobling M, Tyler-Smith C (1995) Father and sons - the Y chromosome and human evolution. Trends Genet 11:449-456 
Jobling MA, Tyler-Smith C (2000) New uses for new haplotypes: the human Y chromosome, disease and selection. Trends Genet 16:356362

Karafet TM, Zegura SL, Posukh O, Osipova L, Bergen A, Long J, Goldman D, Klitz W, Harihara S, de Knijff P, Wiebe V, Griffiths RC, Templeton AR, Hammer MF (1999) Ancestral Asian source(s) of new world Y-chromosome founder haplotypes. Am J Hum Genet 64:817-831

Kayser M, Roewer L, Hedman M, Henke L, Henke J, Brauer S, Kruger C, Krawczak M, Nagy M, Dobosz T, Szibor R, de Knijff P, Stoneking M, Sajantila A (2000) Characteristics and frequency of germline mutation at microsatellite loci from the human Y chromosome, as revealed by direct observation in father/son pairs. Am J Hum Genet 66:1580-1588

Kotliarova SE, Toda T, Takenaka O, Matsushita I, Hida A, Shinka T, Goto J, Tokunaga K, Nakagome Y, Nakahori Y (1999) Novel (CA), marker DXYS241 on the nonrecombinant part of the human $\mathrm{Y}$ chromosome. Hum Biol 71:263-277

Mathias N, Bayes M, Tyler-Smith C (1994) Highly informative compound haplotypes for the human Y chromosome. Hum Mol Genet 3:115-123

Nakagome Y, Young SR, Akane A, Numabe H, Jin DK, Yamori Y, Seki S, Tamura T, Nagafuchi S, Shiono H, Nakahori Y (1992) A Y- associated allele may be characteristic of certain ethnic groups in Asia. Ann Hum Genet 56:311-314

Ngo KY, Vergnaud G, Johnsson C, Lucotte G, Weissenbach J (1986) A DNA probe detecting multiple haplotypes of the human Ychromosome. Am J Hum Genet 38:407-418

Parra E, Shriver MD, Soemantri A, McGarvey ST, Hundrieser J, Saha N, Deka R (1999) Analysis of five Y-specific microsatellite loci in Asian and Pacific populations. Am J Phys Anthropol 110:1-16

Sambrook J, Fritsh E, Maniathis T (1989) Molecular cloning: a laboratory manual. Cold Spring Harbor Laboratory Press

Shinka T, Tomita K, Toda T, Kotliarova SE, Lee J, Kuroki Y, Jin DK, Tokunaga K, Nakamura H, Nakahori Y (1999) Genetic variations on the $\mathrm{Y}$ chromosome in the Japanese population and implications for modern human Y chromosome lineage. J Hum Genet 44:240245

Takahashi E, Yamakawa K, Nakamura Y, Hori T (1992) A highresolution cytogenetic map of human chromosome 3: localization of 291 new cosmid markers by direct R-banding fluorescence in situ hybridization. Genomics 13:1047-1055

Underhill PA, Jin L, Zemans R, Oefner PJ, Cavalli-Sforza LL (1996) A pre-Columbian Y chromosome-specific transition and its implications for human evolutionary history. Proc Natl Acad Sci USA 93:196-200 